\title{
A review of antimicrobial resistance in East Africa
}

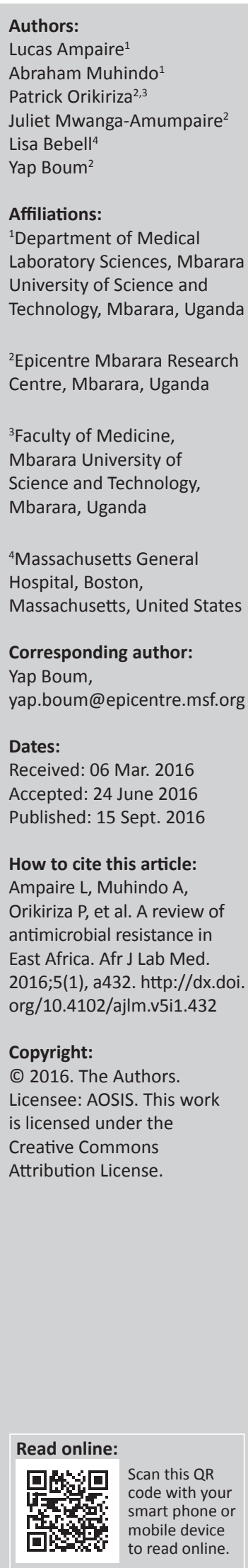

Background and objectives: Knowledge of local and regional antimicrobial resistance (AMR) is important for clinical decision making. However, surveillance capacity for AMR is lacking throughout East Africa, and current AMR data are sparse. We sought to address this gap by summarising all available high-quality data on AMR in the East Africa region.

Method: We searched the PubMed database and African Journals Online archives in April and May 2015 using the search term 'antimicrobial resistance AND sub-Saharan Africa' to find articles published from 2005 onwards. Only full-text articles in English were included.

Results: We included 12 published articles in our analysis. Most articles were on bloodstream infections, hospital-based and cross-sectional in design; a majority described either community- or hospital-acquired infections. High levels of AMR to commonly-used antibiotics were reported, including 50\% - 100\% resistance to ampicillin and cotrimoxazole infections, emerging resistance to gentamicin $(20 \%-47 \%)$ and relatively high levels of resistance to ceftriaxone $(46 \%-69 \%)$ among Gram-negative infections. Much of the resistance was reported to be in Klebsiella species and Escherichia coli. Among Gram-positive infections, extensive resistance was reported to ampicillin (100\%), gentamicin and ceftriaxone $(50 \%-100 \%)$, with methicillin-resistant Staphylococcus aureus prevalence ranging from $2.6 \%-4.0 \%$.

Conclusion: Overall, bacterial resistance was reported among commonly-used antibiotics (ampicillin, gentamicin and ceftriaxone), raising concern that these antibiotics may no longer be useful for treating moderate or severe bacterial infections in East Africa. Thus, empirical treatment of bacterial infections needs to be reconsidered and guided by local assessment of AMR. Improvements in the limited amount of quality data and lack of harmonisation in assessing the burden of AMR are also needed.

\section{Introduction}

Without urgent, coordinated action by many stakeholders, the world is headed for a post-antibiotic era, in which common infections and minor injuries which have been treatable for decades can once again kill. (Dr Keiji Fukuda, WHO Assistant Director-General for Health Security)

The benefits of appropriate antibiotic use to treat bacterial infections are well established, although all antibiotic use carries a risk of inducing antimicrobial resistance (AMR). Throughout East Africa there is a heavy burden of community-acquired infectious disease. ${ }^{1}$ Unfortunately, the surveillance capacity for AMR is minimal in most East African countries, and current data on AMR patterns of common pathogenic bacteria are sparse. ${ }^{2}$ In addition, World Health Organization (WHO) surveillance reports indicate that there is inadequate coordination and harmonisation, compromising the ability to assess and monitor the situation. ${ }^{3}$ As a result, in these resource-constrained settings, the choice of antibiotic is often not based on known bacterial susceptibilities. Limited capacity for microbiology testing in East Africa coupled with a high burden of life-threatening bacterial infections reinforces a pattern of antibiotic prescription that is largely empirical, where AMR is detected only by therapeutic failure. Compounding the problem is the small repertoire of antimicrobials available in these settings, which are often of poor quality, when not counterfeit. In addition, in low-resource settings, antibiotics are often sold over the counter with minimal product regulation, oversight or quality control. ${ }^{4}$ The above, coupled with poor hygiene and infection control practices, may also spread community and/or hospital-acquired drug-resistant pathogens, further exacerbating the problem. ${ }^{5}$

The WHO global report ${ }^{3}$ on AMR indicates that resistance of common bacteria has reached alarming levels in many parts of the world. Furthermore, the report shows high proportions of resistance to third-generation cephalosporins and carbapenems: up to 54\% among Escherichia coli and Klebsiella pneumoniae. Unfortunately, in East Africa, few good studies exist documenting the 
extent of AMR. The Global Antibiotic Resistance Partnership conducted by the Uganda National Academy of Sciences recently revealed worsening trends of resistance and diminishing effectiveness of antibiotics in Uganda. ${ }^{6}$ Some affordable drugs, such as penicillin $\mathrm{G}$ and cotrimoxazole, have been reported to have resistance at or near $100 \%{ }^{6}$

Although such reports are concerning, the burden of AMR in the East Africa region is not well published. Additionally, knowledge of the situation in many parts of the world further complicates the problem. ${ }^{3}$ Better knowledge of the burden and proportion of infections caused by drugresistant bacteria in low-resource settings would raise awareness of the need to prevent the rise and spread of drug resistance. Understanding current levels of AMR throughout East Africa could improve clinical practice by guiding empirical antibiotic choice. Toward this end, we reviewed the available evidence on the burden of AMR among bacterial pathogens in East Africa in order to inform current clinical practice and future research interventions to address antibiotic resistance.

\section{Methods \\ Literature review}

We searched the PubMed database and African Journals Online archives in April and May 2015. We used the term 'antimicrobial resistance AND sub-Saharan Africa' to find articles published from 2005 onwards. Only articles in English were included.

\section{Study selection criteria}

Full-text articles were included if they reported the proportion of antibiotic resistance among clinical isolates of pathogenic bacteria collected from inpatients and outpatients in any of the following East African countries: Uganda, Kenya, Tanzania, Rwanda, Ethiopia and Democratic Republic of Congo. Eligible studies were required to describe the patient population studied, organisms isolated, specific laboratory methods used for the determination of pathogen antimicrobial sensitivity patterns, and an interpretation of the specific minimum inhibitory concentration breakpoints or the diameter of the zone of inhibition of the antibiotics tested as described by the Clinical and Laboratory Standards Institute. ${ }^{7,8}$ Both adult and paediatric patient populations were included, but case reports were excluded from the review as has been done previously. ${ }^{9}$ For overlapping studies reporting on the same clinical isolates, only the study with the largest sample size was included. In an effort to incorporate contemporary, relevant AMR data, only studies published from 2005 onwards were included in the review.

\section{Data extraction}

The extracted data included bacterial species isolated, the number of isolates tested for AMR, specific antibiotics tested for resistance, and percentage of organisms resistant to each antibiotic. Extracted data were grouped on the basis of whether they caused bloodstream infections or other infections.

\section{Results}

We initially identified 150 articles: 140 from PubMed and 10 from African Journals Online. Full-text articles were available for 34 papers identified by the search. Of the remaining 116 manuscripts, only abstracts were freely available for 105 articles; 11 presented information on antituberculosis drug resistance and lacked information on nonmycobacterial infections, which rendered them ineligible for inclusion in this review. Of the 34 full-text articles available, 22 were excluded, because the data presented were from non-East African countries that were inseparable from data presented about East African countries $(n=5)$ or their laboratory methods were not well defined $(n=17)$ (Figure 1). The remaining 12 articles were included in this review, six describing AMR patterns in Uganda, ${ }^{10,11,12,13,14,15}$ five in Ethiopia ${ }^{16,17,18,19,20}$ and one in Tanzania ${ }^{21}$ (Table 1). Neither studies from Rwanda nor studies from the Democratic Republic of the Congo met inclusion criteria for this review. All studies were hospital-based and crosssectional in design, and the majority described both community- and hospital-acquired infections. Four studies presented data on bloodstream infection, seven focused on other infections excluding bloodstream infections and one reported clinical specimens from multiple anatomical sites.

\section{Antimicrobial resistance patterns Bloodstream infections}

According to the disk diffusion methods used in studies included in this review, pathogens exhibited relatively high levels of resistance to antibiotics commonly used in East Africa. For Gram-negative organisms (Table 2), 50\% - 100\% resistance was reported to ampicillin and cotrimoxazole, two of the

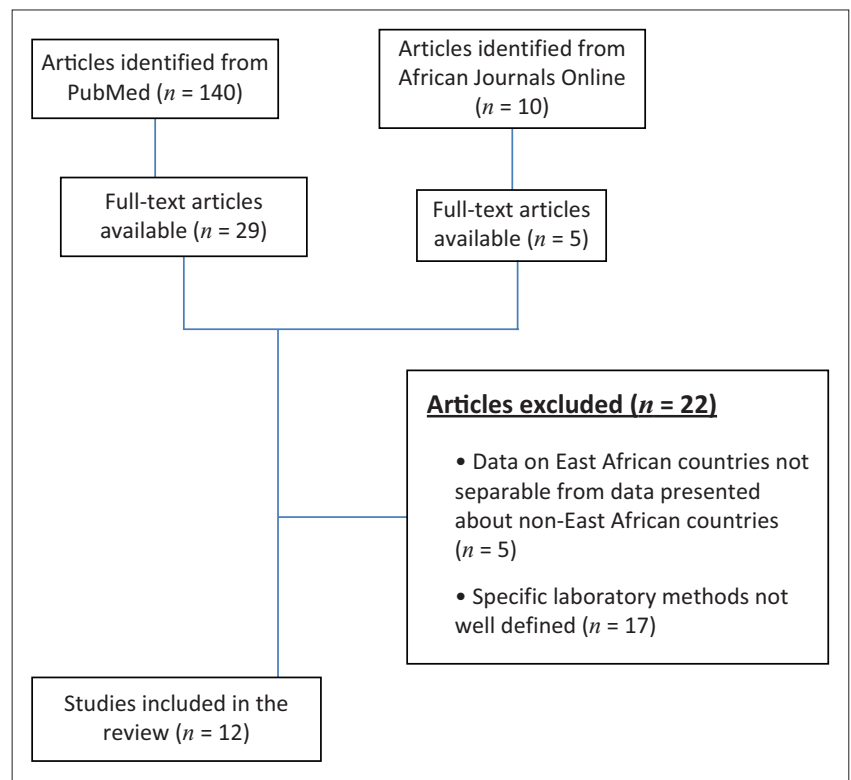

FIGURE 1: Selection of publications for inclusion in this review. 
TABLE 1: Summary of East Africa-based studies included in the analysis.

\begin{tabular}{|c|c|c|c|c|c|c|}
\hline \multirow[t]{2}{*}{ Country } & \multirow[t]{2}{*}{ Year } & \multicolumn{2}{|c|}{ Bacterial species $(N)$} & \multirow[t]{2}{*}{ Patient population } & \multirow{2}{*}{$\begin{array}{l}\text { No. of } \\
\text { patients }\end{array}$} & \multirow{2}{*}{$\begin{array}{l}\text { Reference } \\
\text { No. }\end{array}$} \\
\hline & & Gram-positive & Gram-negative & & & \\
\hline \multicolumn{7}{|c|}{ Patients with bloodstream infections } \\
\hline Uganda & 2006 & 31 & 13 & Severely malnourished, HIV-positive children & 450 & 13 \\
\hline Uganda & 2006 & 76 & 20 & Neonates with confirmed septicemia & 293 & 10 \\
\hline Ethiopia & 2013 & 17 & 17 & Children and adults with suspected septicemia & 390 & 17 \\
\hline Tanzania & 2005 & 66 & 103 & Children with fatal septicemia & 1798 & 21 \\
\hline \multicolumn{7}{|c|}{ Patients with other, non-bloodstream infections } \\
\hline Ethiopia & 2012 & 12 & 22 & Pregnant women with UTIs & 367 & 16 \\
\hline Ethiopia & 2012 & - & 22 & Post-operative nosocomial infections & 294 & 19 \\
\hline Ethiopia & 2014 & - & 21 & UTI in obstetric fistula patients & 53 & 18 \\
\hline Ethiopia & 2014 & - & 35 & Stool isolates in children $<5$ years with diarrhoea & 158 & 20 \\
\hline Uganda & 2011 & 66 & - & MRSA from surgical patients & 122 & 11 \\
\hline Uganda & 2013 & 95 & 209 & Surgical hospitalised patients & 314 & 14 \\
\hline Uganda & 2009 & - & 123 & Neisseria gonorrhoeae isolates from sex workers & 123 & 15 \\
\hline Uganda & 2013 & 300 & - & $\begin{array}{l}\text { Clinical isolates of Staphylococcus aureus from } \\
\text { various clinical specimens }\end{array}$ & 300 & 12 \\
\hline
\end{tabular}

MRSA, methicillin-resistant Staphylococcus aureus; UTI, urinary tract infection.

TABLE 2: Antibiotic resistance patterns among patients with bloodstream infections.

\begin{tabular}{|c|c|c|c|c|c|c|c|c|c|}
\hline \multirow[t]{2}{*}{ Bacteria } & \multirow[t]{2}{*}{ No. of species } & \multicolumn{6}{|c|}{ Percentage resistant by Kirby Bauer disk diffusion method } & \multirow[t]{2}{*}{ Country } & \multirow[t]{2}{*}{ Reference } \\
\hline & & AMP & SXT & CHLO & PEN & CRO & GENT & & \\
\hline \multicolumn{10}{|l|}{ Gram-positive } \\
\hline \multirow[t]{4}{*}{ Staphylococcus aureus } & 20 & 35 & 77 & 37 & - & - & 12 & Uganda & 11 \\
\hline & 69 & 88 & - & 73 & - & - & 4 & Uganda & 10 \\
\hline & 17 & 47 & 58 & 23 & - & - & 29 & Ethiopia & 17 \\
\hline & 30 & 100 & - & - & - & - & - & Tanzania & 21 \\
\hline \multirow[t]{2}{*}{ Enterococcus faecalis } & $9 \dagger$ & - & - & 62 & 83 & - & 44 & Tanzania & 21 \\
\hline & $6 \%$ & - & - & 67 & 25 & - & 33 & Tanzania & 21 \\
\hline \multirow[t]{2}{*}{ Enterococcus faecium } & $12 \dagger$ & 75 & 63 & - & 90 & - & 23 & Tanzania & 21 \\
\hline & $9 \$$ & 89 & 100 & - & 100 & - & 77 & Tanzania & 21 \\
\hline Streptococcus pneumoniae & 11 & 27 & 100 & 27 & - & - & - & Uganda & 13 \\
\hline Streptococcus agalactiae & 7 & 14 & - & 14 & - & - & 57 & Uganda & 10 \\
\hline \multicolumn{10}{|l|}{ Gram-negative } \\
\hline \multirow[t]{5}{*}{ Escherichia coli } & 6 & 83 & 100 & 50 & - & - & - & Uganda & 13 \\
\hline & 17 & - & - & - & - & - & 29 & Uganda & 10 \\
\hline & 5 & 100 & 40 & 20 & 40 & - & - & Ethiopia & 17 \\
\hline & $24 \dagger$ & 96 & - & - & - & 22 & 29 & Tanzania & 21 \\
\hline & $13 \$$ & 85 & - & - & - & 4 & 46 & Tanzania & 21 \\
\hline \multirow[t]{3}{*}{ Klebsiella spp. } & 8 & 75 & 50 & 62 & - & 62 & 37 & Ethiopia & 17 \\
\hline & $19 \dagger$ & 100 & - & - & - & 26 & 47 & Tanzania & 21 \\
\hline & $34 \$$ & 100 & - & - & - & 15 & 47 & Tanzania & 21 \\
\hline \multirow[t]{3}{*}{ Pseudomonas aeruginosa } & 4 & 100 & 75 & 25 & - & 25 & - & Ethiopia & 17 \\
\hline & $7 \dagger$ & 100 & - & - & - & 80 & 24 & Tanzania & 21 \\
\hline & $6 \$$ & 100 & - & - & - & 100 & 27 & Tanzania & 21 \\
\hline \multirow[t]{2}{*}{ Salmonella spp. } & 5 & 80 & 80 & - & - & - & 20 & Uganda & 13 \\
\hline & 3 & - & - & - & - & - & 33 & Uganda & 10 \\
\hline Haemophilus spp. & 2 & 100 & 100 & 50 & - & - & - & Uganda & 13 \\
\hline
\end{tabular}

AMP, Ampicillin; CRO, Cefuroxime; CHLO, Chloramphenicol; GENT, Gentamicin; PEN, Penicillin; SXT, Trimethoprim-sulfamethoxazole.

$\uparrow$, Hospital-acquired; $\$$, Community acquired.

most frequently-prescribed antibiotics in this region. ${ }^{16}$ High levels of resistance to ampicillin among children with bloodstream infections $(75 \%-100 \%)^{7,10,16}$ were also reported, as were lower, but significant, levels of resistance to gentamicin (20\% - 47\%). ${ }^{7,10,16}$ Among Gram-positive organisms isolated from bloodstream infections, overall relatively low levels of resistance were reported to gentamycin, ampicillin and chloramphenicol $(4 \%-12 \%){ }^{10,11}$ However, studies reporting specifically on hospital-acquired strains noted high-level resistance to ampicillin, gentamycin, chloramphenicol and trimethoprim-sulfamethoxazole $(29 \%))^{11,19}$

\section{Non-bloodstream infections}

\section{Surgical site infections}

Among organisms isolated from surgical site infections in hospitalised patients, Staphylococcus aureus and coagulasenegative Staphylococcus were the most common Grampositive organisms, whereas Klebsiella spp., Proteus spp. and E. coli were the most common Gram-negative organisms ${ }^{10,16,22}$ (Table 3). Multiple studies reported $100 \%$ resistance to ampicillin for surgical site infections among hospitalised adults. ${ }^{16,22}$ There was also notable resistance of Gram-positive 
TABLE 3: Antibiotic resistance patterns among patients with other, non-bloodstream infections

\begin{tabular}{|c|c|c|c|c|c|c|c|c|c|c|c|c|c|c|c|c|}
\hline \multirow[t]{2}{*}{ Bacteria } & \multirow{2}{*}{$\begin{array}{l}\text { No. of } \\
\text { species }\end{array}$} & \multicolumn{13}{|c|}{ Percentage resistant by Kirby Bauer disk diffusion method } & \multirow[t]{2}{*}{ Country } & \multirow[t]{2}{*}{ Reference } \\
\hline & & AMP & SXT & TTC & CHLO & ERY & GENT & AMX & CEFT & CIPRO & DOXY & $\mathbf{F}$ & KAN & $\mathrm{CL}$ & & \\
\hline \multicolumn{17}{|l|}{ Gram-positive } \\
\hline \multirow{2}{*}{$\begin{array}{l}\text { Coagulase-negative } \\
\text { Staphylococci }\end{array}$} & 6 & 50 & 66 & 50 & 16 & - & 16 & 33 & - & 50 & - & 16 & 33 & - & Ethiopia & 16 \\
\hline & 9 & 100 & 11 & 55 & 55 & 55 & 44 & - & 44 & 44 & 33 & - & - & - & Uganda & 11 \\
\hline \multirow{4}{*}{$\begin{array}{l}\text { Staphylococcus } \\
\text { aureus }\end{array}$} & 3 & 66 & 33 & 66 & 33 & - & - & - & - & 33 & - & 33 & - & - & Ethiopia & 16 \\
\hline & 66 & 25 & 50 & 54.7 & 65.6 & 92.2 & 100 & - & - & 98.4 & - & - & - & - & Uganda & 11 \\
\hline & 64 & 100 & 89 & 42 & 15 & 46 & 18 & - & - & - & - & - & - & - & Uganda & 14 \\
\hline & 300 & - & 62 & - & - & 47 & - & - & - & - & - & - & - & 36 & Uganda & 12 \\
\hline $\begin{array}{l}\text { Streptococcus } \\
\text { agalactiae }\end{array}$ & 2 & 50 & 50 & 50 & 50 & - & 50 & 50 & - & 50 & - & - & 50 & - & Uganda & 14 \\
\hline Enterococcus spp. & 23 & 30 & - & 74 & 30 & 65 & 21 & - & - & 60 & - & - & - & - & Uganda & 14 \\
\hline \multicolumn{17}{|l|}{ Gram-negative } \\
\hline \multirow[t]{3}{*}{ Escherichia coli } & 16 & 81 & 56 & 43 & 56 & - & 31 & 75 & - & 18 & - & - & 63 & - & Ethiopia & 16 \\
\hline & 9 & 78 & 67 & 66 & - & - & - & 90 & 55 & 44 & 66 & 22 & 44 & - & Ethiopia & 19 \\
\hline & 6 & 67 & 67 & 100 & 17 & - & 67 & 50 & 50 & 50 & - & - & - & - & Ethiopia & 18 \\
\hline \multirow{2}{*}{$\begin{array}{l}\text { Klebsiella } \\
\text { pneumoniae }\end{array}$} & 39 & 100 & 92 & 76 & 71 & - & 76 & - & 92 & 66 & - & - & - & - & Uganda & 14 \\
\hline & 2 & 100 & 100 & - & 100 & - & 100 & 100 & 100 & 100 & 50 & 50 & 50 & - & Ethiopia & 19 \\
\hline \multirow{3}{*}{$\begin{array}{l}\text { Pseudomonas } \\
\text { aeruginosa }\end{array}$} & 2 & 100 & 50 & 50 & 100 & - & 50 & 50 & - & - & - & - & 50 & - & Ethiopia & 16 \\
\hline & 5 & 100 & 60 & 20 & 80 & - & 40 & 100 & 100 & 40 & 80 & 100 & 60 & - & Ethiopia & 19 \\
\hline & 12 & - & 100 & 100 & - & - & 16 & - & 16 & - & - & - & - & - & Uganda & 14 \\
\hline \multirow[t]{2}{*}{ Proteus mirabilis } & 5 & 100 & 60 & 20 & 80 & - & 40 & 100 & 100 & 40 & 80 & 100 & 60 & - & Ethiopia & 19 \\
\hline & 2 & 50 & 50 & - & 50 & - & - & 100 & - & - & - & 100 & - & - & Ethiopia & 16 \\
\hline \multirow[t]{2}{*}{ Citrobacter freundi } & 13 & 69 & 54 & 62 & 77 & - & 62 & 69 & 46 & 54 & - & - & - & - & Ethiopia & 18 \\
\hline & 2 & 100 & 100 & - & 100 & - & - & 100 & - & 100 & - & - & - & - & Ethiopia & 16 \\
\hline $\begin{array}{l}\text { Salmonella } \\
\text { serogroup A }\end{array}$ & 1 & - & - & - & - & - & - & - & 100 & - & - & - & - & - & Ethiopia & 20 \\
\hline $\begin{array}{l}\text { Salmonella } \\
\text { serogroup B }\end{array}$ & 3 & - & - & - & - & - & - & - & 100 & - & - & - & - & - & Ethiopia & 20 \\
\hline Shigella spp. & 11 & 63 & - & 54 & 9 & 90 & 27 & 100 & 55 & - & - & - & - & - & Ethiopia & 20 \\
\hline $\begin{array}{l}\text { Neisseria } \\
\text { gonorrhoeae }\end{array}$ & 123 & - & - & - & - & - & - & - & - & 81 & - & - & - & - & Uganda & 15 \\
\hline
\end{tabular}

AMP, Ampicillin; AMX, Amoxicillin; CEFT, Ceftriaxone; CHLO, Chloramphenicol; CIPRO, Ciprofloxacin; CL, Clindamycin; DOXY, Doxycycline; ERY, Erythromycin; F, Nitrofurantoin; GENT, Gentamicin; KAN, Kanamycin; SXT, Trimethoprim-sulfamethoxazole; TTC, Tetracycline.

organisms to gentamicin and ceftriaxone in post-operative nosocomial isolates $(50 \%-100 \%)$, with methicillin-resistant Staphylococcus aureus (MRSA) prevalence ranging from $2.6 \%-4.0 \%{ }^{16}$

\section{Urinary tract infections}

High-level resistance to ampicillin $(50 \%-100 \%)$ was seen in urinary tract infections, where E. coli was the most common pathogen. ${ }^{16,18}$ Citrobacter freundii was a major cause of urinary tract infections in one study focused on obstetric fistula patients, with resistance to ampicillin, gentamicin, and ceftriaxone ranging from $46 \%-69 \%{ }^{18}$ Other causative organisms of urinary tract infections, such as Klebsiella spp., Enterobacter spp. and Proteus spp., also showed significant resistance to ampicillin, gentamycin and ceftriaxone, some of the most commonly-used antibiotics in East Africa. ${ }^{16,18}$ There was also high-level resistance reported of Neisseria gonorrhoeae to ciprofloxacin $(81 \%)$ among sex workers in Uganda. ${ }^{21}$

\section{Gastrointestinal tract infections}

Salmonella spp. in stool isolates from children under five years of age demonstrated complete resistance to ceftriaxone $(100 \%)$. From the gastrointestinal tract, the commonly isolated bacteria were Campylobacter spp. and Shigella spp. Campylobacter spp. showed moderate amounts of resistance to ampicillin (30\%) and high-level resistance to gentamicin (70\%). Among Shigella spp., relatively high numbers were resistant to ampicillin (63\%), although resistance to gentamycin was lower at $27 \%$ in one Ethiopian study. ${ }^{20}$

\section{Multiple body sites}

One study from Uganda on phenotypic clindamycin resistance found that $109(36 \%)$ of S. aureus isolates were resistant to clindamycin, of which $9(3 \%)$ were constitutively resistant and $100(33.3 \%)$ were inducibly resistant. In this study, S. aureus also showed significant resistance to trimethoprim-sulfamethoxazole (62\%) and oxacilin (36\%), with a demonstrated prevalence of MRSA equal to $36 \% .^{12}$ Resistance to vancomycin, one of the last-line drugs for treating MRSA, was also found $(7.3 \%){ }^{12}$

\section{Discussion}

In this review, we summarise the findings of 12 studies that demonstrate significant resistance across the East Africa region to antibiotics important for everyday use. Overall, although AMR varies throughout the region, we found that most Gram-negative organisms have limited susceptibility to 
ampicillin, ceftriaxone and gentamicin, which are commonlyused first-line empirical antibiotics in this region and recommended by the WHO Integrated Management of Childhood Illness for treatment of severely-ill infants. There was also significant resistance to cotrimoxazole, penicillins, quinolones, cephalosporins and aminoglycosides among Gram-positive organisms.

Several published papers we reviewed reported single bacterial isolates resistant to multiple antibiotics. Antibiotic resistance to multiple drugs was most common among Gramnegative organisms isolated from hospital-acquired infections in post-operative patients and hospitalised adults. ${ }^{16,23}$ However, the susceptibility of Gram-negative organisms to ciprofloxacin was generally reported to be good; thus, this may be the drug of choice for empirical use against post-operative nosocomial infections with Gram-negative organisms. The finding of multi-drug resistance in this population suggests that efforts to promote appropriate antibiotic use and microbiological sampling of infected patients should be targeted to these groups in low-resource settings.

The evidence presented here indicates that AMR, especially to the widely-used antibiotics (ampicillin, tetracyclines and trimethoprim-sulfamethoxazole), is prevalent and common in East Africa and may be a growing problem, especially among hospitalised and post-operative patients. However, resistance is likely under-reported in this region as noted by the WHO Global Report on AMR in $2014,{ }^{3}$ due to limited availability of diagnostic testing, microbiology support and limited comparability of laboratory standards. Many of the same factors leading to the inability to test clinical isolates for antimicrobial susceptibility contribute to antibiotic overuse and misuse when laboratory data are lacking and can contribute to exacerbation of AMR.

Even when information about AMR is available, it may not be properly communicated to those prescribing medications in East Africa, due to inadequate national laboratory strategic plans throughout the region. In addition, guidelines regarding appropriate selection of drugs are inadequate. ${ }^{11,18}$ Compounding these problems is a lack of rigorous infection control procedures, all of which could lead to the development and spread of antibiotic resistant bacteria. These factors combine to support the spread of existing AMR throughout East Africa.

\section{Preventing the development and spread of antimicrobial resistance}

AMR is likely to become an even greater problem in East Africa and may be exacerbated by overuse of antibiotics, the lack of oversight of antibiotic prescription, and the paucity of relevant local data on AMR. To address these issues, existing antimicrobial stewardship programmes should be strengthened or, where they are not yet in place, they should be developed and implemented in all regional referral hospitals in response to these challenges. Based on our findings, an area of particular focus should be hospitalised patients. Existing but limited resources should be directed equally at discovering the causes and at appropriate treatment of infections in this population.

Additionally, there is a need to urgently scale-up training of both laboratory and pharmacy staff in antibiotic stewardship at health facilities where laboratory investigations are available. This is critical in communicating with clinicians, who are the cornerstone of proper management of patients with infections, especially with regard to the use of antibiotics. There is also need to regularly conduct antibiotic resistance surveys to establish evidence-based and locally-relevant antibiotic resistance information that would be helpful in creating guidelines to improve clinical practice.

The implementation of the 2009 WHO global strategy for containment of AMR through inter-continental-wide surveillance programmes as a health systems approach ${ }^{12,23,24,25}$ has met with a number of challenges. In low- and middleincome countries, implementing the strategy has proven difficult, because human and financial resources and microbiology expertise are insufficient. In addition, it is difficult to obtain appropriate sample sizes for an accurate representation of resistance patterns. Novel approaches to antimicrobial surveillance are therefore needed for lowresource settings, which include the development of surveillance programmes utilising smaller sample sizes to provide locally-relevant AMR patterns and to encourage appropriate empirical antimicrobial therapy. ${ }^{26}$ Moreover, the development of new point-of-care diagnostic tools able to detect AMR in a cost-effective way will improve patient management and limit the emergence of drug resistance.

Lastly, from among the total of 150 publications we identified, we considered only 12 due to the lack of standardisation and quality of the methodology and reporting. This highlights the scarcity of good quality data that could allow stakeholders to assess the real burden of AMR. Thus, better standardised research protocols are needed to evaluate the emergence of AMR in different settings to obtain comparable results and implement tailor-made interventions.

\section{Conclusion}

Based on the findings in this review, resistance to commonlyused antibiotics is prevalent in East Africa. Multi-drug resistance has been noted as a rising threat in the region and threatens to further complicate the drug resistance burden, especially for non-bloodstream infections where a single isolate may be resistant to more than one antibiotic drug of choice in different or similar drug lines.

Data from interventional studies designed to reduce AMR are particularly lacking in the East African context, where infectious disease prevalence is high. The profound lack of data on hospital-acquired infections and prevalence of AMR in low-income East African countries calls for vigorous investigation and surveillance to better define the problem. There is a need for countries to promote acceptance of 
antimicrobial stewardship as a programmatic strategy, including pharmacy management, laboratory quality control, complete microbiology investigations and creation and dissemination of regional standard antibiograms.

\section{Acknowledgements}

We are grateful to Dan Nyehangane and Associate Professor Apecu O. Richard for their critical review of the manuscript and the Uganda Research Student Support Fund for their assistance.

\section{Competing interests}

The authors declare that they have no financial or personal relationships which may have inappropriately influenced them in writing this article.

\section{Authors' contributions}

This work was carried out in collaboration between all authors. Y.B. was the project leader. L.A. and A.M. performed the literature search, data analysis, and wrote the first draft of the manuscript and managed manuscript revisions. L.B. participated in data analysis and manuscript writing and revisions. P.O., J.M.-A. and Y.B. participated in manuscript writing and revisions. All authors read and approved the final manuscript.

\section{References}

1. Murray CJL, Ezzati M, Flaxman AD, et al. GBD 2010: a multi-investigator collaboration for global comparative descriptive epidemiology. Lancet.
2012;380(9859):2055-2058. http://dx.doi.org/10.1016/S0140-6736(12)62134-5

2. Okeke IN, Aboderin OA, Byarugaba DK, et al. Growing problem of multidrug resistant enteric pathogens in Africa. Emerg Infect Dis. 2007;13(11):1640-1646. http://dx.doi.org/10.3201/eid1311.070674

3. World Health Organization. Antimicrobial resistance: global report on surveillance. WHO Press: Geneva, Switzerland; 2014.

4. Cockburn R, Newton PN, Agyarko EK, et al. The global threat of counterfeit drugs: why industry and governments must communicate the dangers. PLoS Med. 2005;2(4):e100. http://dx.doi.org/10.1371/journal.pmed.0020100

5. Laxminarayan R, Bhutta Z, Duse A, et al. Drug resistance. In: Jamison D, Breman JG, Measham AR, et al., editors. Disease control priorities in developing countries. New York: Oxford University Press. 2006; pp. 1031-1051.

6. Otage S. Antibiotic resistance on the rise, say doctors. Daily Monitor [newspaper online]. 2015 Sep 17 [cited 2015 Sep 20]. Available from: http://www.monitor. co.ug/News/National/Antibiotic-resistance-on-the-rise-say-doctors-/-/ 688334/2873728/-/4yqad1/-/index.html
7. Clinical and Laboratory Standards Institute. Performance standards for antimicrobial disk susceptibility tests; approved standard: 10 th ed. CLSI document M02-A10. CLSI: Wayne, PA; 2009.

8. Clinical and Laboratory Standards Institute. Performance standards for antimicrobial susceptibility testing: 22nd informational supplement. CLSI document M100-S22. CLSI: Wayne, PA; 2012.

9. Morgan DJ, Okeke IN, Laxminarayan R, et al. Non-prescription antimicrobial use worldwide: a systematic review. Lancet Infect Dis. 2011;11(9):692-701. http:// dx.doi.org/10.1016/S1473-3099(11)70054-8

10. Mugalu J, Nakakeeto MK, Kiguli S, et al. Aetiology, risk factors and immediate outcome of bacteriologically confirmed neonatal septicaemia in Mulago hospital, Uganda. Afr Health Sci. 2006;6(2):120-126.

11. Kitara LD, Anywar AD, Acullu D, et al. Antibiotic susceptibility of Staphylococcus aureus in suppurative lesions in Lacor Hospital, Uganda. Afr Health Sci. 2011;11 Suppl 1:S34-39. http://dx.doi.org/10.4314/ahs.v11i3.70068

12. Mwambi B, Iramiot J, Bwanga $F$, et al. Clindamycin resistance among Staphylococcus aureus isolated at Mbarara Regional Referral Hospital, in South Western Uganda. Br Microbiol Res J. 2014;4(12):1335-1344. http://dx.doi. org/10.9734/BMRJ/2014/10572

13. Bachou H, Tylleskär T, Downing R, et al. Severe malnutrition with and without HIV 1 infection in hospitalised children in Kampala, Uganda: differences in clinical features, haematological findings and CD4+ cell counts. Nutr J. 2006;5:27. http:// dx.doi.org/10.1186/1475-2891-5-27

14. Seni J, Najjuka CF, Kateete DP, et al. Antimicrobial resistance in hospitalized surgical patients: a silently emerging public health concern in Uganda. BMC Res Notes. 2013;6:298. http://dx.doi.org/10.1186/1756-0500-6-298

15. Vandepitte J, Hughes P, Matovu G, et al. High prevalence of ciprofloxacin-resistant gonorrhea among female sex workers in Kampala, Uganda (2008-2009). Sex Transm Dis. 2014;41(4):233-237. http://dx.doi.org/10.1097/OLQ.0000000000000099

16. Demilie T, Beyene G, Melaku S. Urinary bacterial profile and antibiotic susceptibility pattern among pregnant women in north west Ethiopia. Ethiop J Health Sci. 2012;22(2):121-128

17. Dagnew M, Yizmaw G, Gizachew M, et al. Bacterial profile and antimicrobia susceptibility pattern in septicemia suspected patients attending Gonda University Hospital, Northwest Ethiopia. BMC Res Notes. 2013;6:283. http://dx. doi.org/10.1186/1756-0500-6-283

18. Wondimeneh $\mathrm{Y}$, Muluye $\mathrm{D}$, Alemu A, et al. Urinary tract infection among obstetric fistula patients at Gondar University Hospital, Northwest Ethiopia. BMC Womens Health. 2014;14:12. http://dx.doi.org/10.1186/1472-6874-14-12

19. Mulu W, Kibru G, Beyene G, et al. Postoperative nosocomial infections and antimicrobial resistance pattern of bacteria isolates among patients admitted at Felege Hiwot Referral Hospital, Bahirdar, Ethiopia. Ethiop J Health Sci. 2012; 22(1):7-18.

20. Mulatu G, Beyene G, Zeynudin A. Prevalence of Shigella, Salmonella and with diarrhea in Hawassa town, south Ethiopia. Ethiop J Health Sci. with diarrhea in Hawassa town, south Ethiopia. Ethiop
2014;24(2):101-108. http://dx.doi.org/10.4314/ejhs.v24i2.1

21. Blomberg B, Jureen R, Manji KP, et al. High rate of fatal cases of pediatric septicemia caused by gram-negative bacteria with extended-spectrum beta-
lactamases in Dar es Salaam Tanzania. J Clin Microbiol. 2005;43(2):745-749. http://dx.doi.org/10.1128/JCM.43.2.745-749.2005

22. Nambatya JL, Nyairo $S$, Bironse $M$, et al. Antibiotic use knowledge and behavior at a Ugandan University. Int J Infect Control. 2011;7(4):7 pages.

23. Duse AG. The Global Antibiotic Resistance Partnership (GARP). S Afr Med J. 2011;101(8 Pt 2):551.

24. Kimang'a AN. A situational analysis of antimicrobial drug resistance in Africa: are we losing the battle? Ethiop J Health Sci. 2012;22(2):135-143.

25. World Health Organization. Country pharmaceutical situations. WHO Press: Geneva, Switzerland; 2009.

26. World Health Organization. WHO global strategy for containment of antibiotic resistance. WHO Press: Geneva, Switzerland; 2001. 